\title{
DAMPAK PENERAPAN BASIS AKRUAL TERHADAP KUALITAS TRANSPARANSI FISKAL PEMERINTAH
}

\author{
Donny Maha Putra \\ Direktorat Jenderal Perbendaharan \\ Sudarto \\ Staf Ahli Bidang Organisasi, Birokrasi dan Teknologi Informasi, Kementerian Keuangan \\ Alamat korespondensi: donnymp@kemenkeu.go.id
}

\begin{abstract}
The purpose of this paper is to measure how effective the application of accrual basis is on the Indonesian government accounting system and its impact on the quality of fiscal transparency in the Indonesian government. The effectiveness was measured in the context of policies, people, processes and systems. Survey in this study was conducted in 85 ministries, involving 149 respondents at accounting unit using questionnaire instruments and interviews with 77 experts. Data analysis was conducted using Structural Equation Modeling method. The results of the study revealed that although the effectiveness of the implementation of accrual accounting is still at an average level, it has a significant impact on the quality of fiscal transparency of government.
\end{abstract}

KATA KUNCI:

Akuntansi Akrual, Transparansi Fiskal, Laporan Keuangan, Pemerintah, Indonesia

\section{ABSTRAK}

Tujuan makalah ini untuk mengukur seberapa efektif penerapan basis akrual pada sistem akuntansi pemerintah Indonesia dan dampaknya terhadap kualitas transparansi fiskal. Efektifitas diukur dalam konteks Polices, People, Processes dan Systems. Penelitian ini dilakukan di 85 Kementerian Negara/Lembaga (K/L) melibatkan 149 responden menggunakan instrumen kuesioner dan wawancara mendalam dengan 77 ahli. Analisis data menggunakan pendekatan Statistik Deskriptif dan Statistik Inferensial dengan metode Structural Equation Modeling (SEM). Hasil penelitian mengungkapkan bahwa meskipun efektifitas penerapan basis akuntansi akrual masih berada di level cukup, namun berdampak signifikan terhadap kualitas transparansi fiskal pemerintah. Dampak tersebut terlihat nyata dalam hal pelaporan fiskal dan perkiraan fiskal dan anggaran pemerintah menjadi lebih baik. Namun dalam hal pengelolaan dan analisis resiko fiskal belum terlihat maksimal.

\section{KLASIFIKASI JEL:}

M41, M48

CARA MENGUTIP: Putra, D.M., \& Sudarto (2019). Dampak penerapan basis akrual terhadap kualitas transparansi fiskal pemerintah. Indonesian Treasury Review: Jurnal Perbendaharaan, Keuangan Negara Dan Kebijakan Publik, 4(3), $219-231$. 


\section{PENDAHULUAN}

Tujuan negara-negara di dunia menerapkan basis akuntansi akrual di semua sub-sektor pemerintahan adalah untuk menjamin proses pelaporan keuangan, penganggaran, dan proyeksi fiskal pemerintah menjadi lebih baik (Beechy, 2007; Heald \& Hodges, 2018). Pelaporan keuangan pemerintah yang transparan berdampak jangka panjang terhadap setiap keputusan pemerintah dalam pertanggungjawaban anggaran negara ( $\mathrm{PwC}$, 2014). Penelitian Bastani dkk (2012) menjelaskan bahwa negara yang konsisten menerapkan basis akrual, mampu memberikan transparansi pelaporan keuangan, menekan biaya operasional dan dapat mengoptimalkan keputusan di masa depan.

Ernst \& Young (2012) menyatakan bahwa metode akuntansi saja tidak menjamin pemerintah akan selalu dapat membuat keputusan yang tepat. Namun demikian, kesediaan untuk meningkatkan transparansi dan akuntabilitas informasi keuangan pemerintah dengan metode akuntansi yang komprehensif, tentu merupakan langkah yang benar. Pandangan ini tidak lepas dari kemampuan basis akrual secara komprehensif menyajikan informasi tentang aset dan kewajiban pemerintah, kinerja keuangan, dan arus kas pemerintah yang berdampak terhadap ekonomi jangka panjang dan keputusan politik pemerintah (Irwin, 2012; PwC, 2013).

Adopsi akrual, seperti negara lainnya di dunia juga dilakukan pemerintah Indonesia, dengan harapan transparansi fiskal pemerintah menjadi lebih baik (Harun \& Robinson, 2010; Harun dkk., 2012; Cavanagh dkk., 2016; Heald \& Hodges, 2018; Ismail dkk., 2018). Namun dalam praktiknya, dampak implementasi terhadap capaian level transparansi fiskal pemerintah masih belum optimal (BPK, 2016), salah satunya, dalam hal keterbukaan anggaran yang masih belum memadai (IBP, 2016). Begitu pula, hal pengungkapan sebagai salah satu indikator transparansi fiskal masih belum terlalu baik dan perlu upaya untuk terus meningkatkannya (Sukmadilaga dkk, 2015).

Penerapan basis akrual, ternyata lebih kompleks dibandingkan basis kas (Ismail dkk, 2018). Penelitian PwC (2013) di 100 negara yang melakukan transisi dari basis kas ke basis akrual, mengungkapkan, terdapat 55 persen isu terkait People, 46 persen isu Systems, dan 27 persen isu terkait Commitment. Isu ini secara faktual tidak terbantahkan bahwa di Indonesia penerapan basis akuntansi akrual masih belum sepenuhnya efektif. Hasil audit Badan Pemeriksaan Keuangan (BPK) menemukan 1.677 permasalahan dari 166 laporan hasil pemeriksaan Laporan Keuangan Pemerintah, penyebabnya antara lain kesalahan dalam penyajian akun-akun akrual (BPK, 2017). Permasalahan ini terjadi karena keterbatasan akuntan pemerintah yang kompeten dan profesional (Harun \& Robinson, 2010; Halim \& Kusufi, 2012), kurangnya komitmen pimpinan (Amriani, 2014; Hassan, 2015; Ratifah dan Mulyani, 2016; Firmansyah, 2016), dan dukungan sistem informasi (Giovanelli, Rotondo, \& Caffù, 2016; Mulyani dkk, 2016; Tanjeh, 2016) yang belum memadai.

Literatur yang membahas efektivitas penerapan basis akrual di sektor pemerintah masih sangat terbatas. Penelitian sebelumnya lebih banyak membahas manfaat dan kegunaan penerapan basis akrual (Hodges \& Mellett, 2003; Chan, 2003; Barton, 2007; Deaconu dkk, 2009; Monteiro \& Gomes, 2013; PwC, 2013), hambatan dan tantangan dalam implementasi (Harun \& Robinson, 2010), faktor yang mempengaruhi adopsi (Adhikari \& Mellemvik, 2011; Harun et al., 2012), kesiapan penerapan (Azmi \& Mohamed, 2014), dan penyediaan informasi untuk pengambilan keputusan yang lebih baik (Hyndman \& Connolly, 2011).

Studi Chan (2003), Hodges \& Mellett (2003), Monteiro \& Gomes (2013), Nistor \& Deaconu (2016) lebih fokus menjelaskan peningkatan efisiensi, transparansi dan akuntabilitas. Begitu pula dengan studi Tickell (2010) di Fiji, Tanjeh (2016) di Cameroon, dan PwC (2013) di Malaysia, secara spesifik belum mengukur efektifitas dan dampak penerapan. Padahal ini penting untuk diketahui bagi negara-negara yang sudah menerapkan basis akrual, seperti The United Kingdom, Canada, New Zealand, Australia, The Netherlands, Sri Lanka, Malaysia dan Indonesia (Baker \& Rennie, 2006; Ismail dkk, 2018).

Studi tentang adopsi basis akuntansi akrual pada sektor pemerintah di Indonesia telah banyak dilakukan, seperti Harun \& Robinson (2010) membahas hambatan implementasi, Harun dkk. (2012) membahas legitimasi kelembagaan, Maimunnah (2015) membahas kesiapan dan masalah penerapan. Namun, pasca implementasi akrual secara penuh sejak tahun 2015 belum ditemukan penelitian yang secara spesifik mengukur efektivitas penerapan basis akrual dari sudut pandang kebijakan, proses transisi, sumber daya manusia, dan sistem yang berdampak terhadap transparansi fiskal pemerintah. Hal ini menjadi motivasi besar bagi penulis untuk 
melanjutkan studi (Harun \& Robinson, 2010; Harun dkk, 2012; Maimunnah, 2015) dengan harapan, hasil penelitian ini dapat memberikan bukti empiris sebagai tambahan literatur yang secara teoritis masih sangat terbatas. Di samping itu, hasil penelitian ini diharapkan dapat berkontribusi sebagai referensi akademis terhadap perbaikan dalam menyusun model kebijakan dalam penerapan basis akrual pada sistem akuntansi pemerintah di Indonesia.

\section{LANDASAN TEORI}

\subsection{Institutional Theory}

Institutional Theory memberikan wawasan tentang bagaimana praktik yang terbaik disebarluaskan dan dilembagakan (DiMaggio \& Powell, 1983), dengan penekanan pada interaksi, dan konteks kelembagaan (Dillard dkk, 2004; Rodrigues \& Craig, 2007; Albu dkk, 2014). Sedangkan pengaruh tekanan kelembagaan terhadap pengembangan praktik organisasi ditandai dengan konsep homogenitas (DiMaggio \& Powell, 1983; Carpenter \& Feroz, 2001; Lounsbury, 2008). Konsep homogenitas dihasilkan dari gagasan bahwa organisasi berusaha untuk mencapai, mempertahankan, dan memperluas legitimasi lembaga dengan keharusan mengadopsi struktur dan praktik yang didukung secara sosial, politis, dan ekonomi (Carpenter \& Feroz, 2001; Ball \& Craig, 2010).

Tekanan kelembagaan berperan menjelaskan bentuk tekanan isomorphis kohersif dari lingkungan eksternal untuk mengadopsi suatu standar yang berlaku umum (DiMaggio \& Powell, 1983; Pina dkk., 2009; Dedoulis, 2016). Dengan demikian, penerapan akrual sebagai standar yang berlaku umum merupakan legitimasi kuat bagi negara dalam mengelola keuangan agar menjadi lebih transparan dan akuntabel (Khan \& Mayes, 2009; Harun dkk, 2012; Heshmat dkk, 2015; Lampe $\mathrm{dkk}, 2015$ ).

\subsection{Penerapan Basis Akuntansi Akrual}

Analisis Heald \& Hodges (2018) menjelaskan bahwa adopsi akrual penting sebagai instrumen kebijakan pemerintah dalam membantu sektor keuangan menghadapi krisis keuangan global. Efektivitasnya dipengaruhi oleh banyak faktor (Lye dkk, 2005; Adhikari \& Mellemvik., 2011; Harun dkk, 2012; Upping \& Oliver, 2012; Azmi \& Mohamed, 2014), dan tergantung tingkat kesiapannya (Azmi \& Mohamed, 2014; Maimunnah, 2015; Ismail dkk, 2018). Berbeda dengan basis kas yang dapat menciptakan distorsi dan rentan terhadap penyalahgunaan keuangan, penipuan, dan penggelapan, penerapan basis akrual diyakini menjadi solusi alternatif yang superior dalam memecahkan masalah tersebut (Aidoo-Buameh, 2014). Basis akrual tidak hanya mencatat penerimaan dan pengeluaran kas saja, tetapi juga mencatat pengakuan pendapatan, biaya, keuntungan, kerugian, dan penambahan atau penurunan aset dan kewajiban serta amortisasi (Dechow \& Skinner, 2000; Gnanarajah, 2014).

Akuntansi akrual merupakan metodologi akuntansi dimana transaksi diakui sebagai kejadian ekonomi yang mendasari pencatatan, terlepas dari waktu penerimaan dan pembayaran kas terjadi (Khan \& Mayes, 2009; Dechow \& Skinner, 2000; Warren dkk, 2014). Efektivitas penerapan basis akuntansi akrual dalam studi ini, diukur menggunakan model penelitian PwC (2014) yang dioperasionalisasikan ke dalam empat dimensi dan tiga belas indikator yaitu: (1) Dimensi Policies dengan indikator: Adapting Existing Financial Rules and Regulations; Documenting Accounting Policies; Developing Comprehensive Guidance and Manuals. (2) Dimensi Processes dengan indikator: Managing the Transition Period and Monitoring; Checking Data Quality During the Reform Process, Designing Quality Control Procedures; Setting Up Data Collection Procedures; Ensuring Compliance with Existing Regulatory Framework. (3) Dimensi People dengan indikator: Inspiring Change of Mentalities and Cultural Change; Ensuring Political Commitment, And Increasing Staff and Public Awareness; Building up Public Sector Accountants Expertise; Developing Training Programes and Allowing Knowledge Transfer. (4) Dimensi Systems dengan indikator: Adapting Existing IT Systems, And/Or Developing New IT Solutions; Translating Organisational Processes into The IT Environment.

\subsection{Transparansi Fiskal}

Transparansi fiskal merupakan pelaporan keuangan pemerintah yang dapat diandalkan, tepat waktu, dan relevan sebagai elemen kunci dalam pengelolaan fiskal yang efektif (Poljašević \& Radisavljević, 2014). Elemen kunci tersebut merupakan instrumen keterbukaan pemerintah kepada publik terhadap akses informasi atas aktivitas pemerintah yang dapat dipercaya, menyeluruh, tepat waktu, mudah dipahami, dan dapat disahkan secara internasional (Alt \& Lassen, 2003; Cottarelli, 2012) sehingga public secara akurat dapat menilai posisi keuangan pemerintah, biaya dan manfaat dari kegiatan pemerintah, nilai ekonomi masa kini, masa depan, dan dampak sosial 
yang ditimbulkan (Mijatovic, 2015; Bernothn \& Wolff, 2008; Granickas, 2013).

Pengukuran kualitas transparansi fiskal dalam penelitian ini, dikembangkan dari literatur (IMF, 2014; Adam, 2015; Mueller dkk, 2015; Siksamat \& Wanitthanankun, 2015; Ionescu \& Buhur, 2016) dioperasionalisasikan kedalam 3 dimensi dan 11 indikator yaitu: (1) Dimensi Fiscal Reporting dengan indikator: coverage; frequency and timeliness; quality; integrity. (2) Dimensi Fiscal Forecasting and Budgeting dengan indikator: comprehensiveness; orderliness; policy orientation; credibility. (3) Dimensi Fiscal Risk Analysis and Management dengan indikator: risk disclosure and analysis; risk management; fiscal coordination.

\subsection{Hipotesis Penelitian}

Penerapan basis akrual pada laporan keuangan memberikan informasi yang lebih relevan, dapat diandalkan, dapat dibandingkan, dan lebih bermanfaat bagi pengguna laporan keuangan dibandingkan dengan basis kas (Heshmat et al., 2015). Lampe, Hilgers \& Ihl (2015) menjelaskan bahwa penerapan basis akuntansi akrual memberikan pengaruh positif dalam memperbaiki transparansi fiskal karena mampu memberikan pandangan yang baik mengenai keuangan pemerintah, aset, dan risiko anggaran. Ahmad et al. (2015) menjelaskan bahwa penerapan akuntansi akrual memberikan manfaat positif terhadap transparansi fiskal berupa kemudahan mendapatkan akses informasi yang akurat, meningkatkan kinerja manajemen, meningkatkan transparansi, dan akuntabilitas kinerja pemerintah. Dengan demikian peneliti berhipotesis:

$H_{1}$ : Penerapan basis akuntansi akrual berpengaruh positif terhadap peningkatan kualitas transparansi fiskal pemerintah.

\section{METODOLOGI PENELITIAN}

\subsection{Waktu dan Sampel Penelitian}

Pengumpulan data dilaksanakan dalam kurun waktu lima bulan, dengan mendatangi secara langsung unit analisis yaitu unit yang menyusun laporan keuangan konsolidasian pada tiap K/L. Setiap responden mendapat penjelasan sebelum menjawab pertanyaan kuesioner, dan dipastikan bahwa responden yang berhak memberikan jawaban adalah orang yang terlibat langsung dalam aktivitas penyusunan laporan keuangan dan memahami proses akuntansi. Metode sampling yang digunakan dalam penelitian ini adalah purposive sampling dengan teknik sensus.

\subsection{Metode Analisis Data}

Analisis data dalam penelitian ini menggunakan analisis deskriptif dan verifikatif. Analisis deskriptif bertujuan untuk memberi gambaran secara kualitatif tentang rangkuman pengamatan terhadap setiap variabel penelitian. Sedangkan Analisis verifikatif dalam penelitian ini menggunakan pendekatan statistik inferensial atau dikenal statistik induktif. Statistik infrensial merupakan teknik statistik yang digunakan untuk menganalisis data sampel dan hasilnya akan diberlakukan untuk populasi melalui pengujian taraf signifikansi data sampel terhadap parameter populasinya yaitu melalui uji t (t-statistics) pada taraf keyakinan (confidence interval). Tingkat signifikansi yang ditetapkan dalam penelitian ini sebesar 95 persen dengan tingkat risiko kesalahan pada $\alpha=5$ persen.

Analisis verifikatif dalam penelitian ini menggunakan pendekatan Structural Equation Modeling (SEM) dengan melakukan pengujian model pengukuran dan pengujian model struktural. Pengujian model pengukuran bertujuan untuk menguji validitas dan reliabilitas instrumen penelitian. Sedangkan pengujian model struktural bertujuan untuk menguji hipotesis penelitian. Sebelum dilakukan kedua pengujian ini, terlebih dahulu akan dilakukan pengujian goodness of fit index untuk mengukur kecocokan model yang dibangun dalam penelitian ini.

\subsection{Validitas dan Reliabilitas Instrumen Penelitian}

Instrumen penelitian ini menggunakan kuesioner untuk mengukur efektivitas penerapan basis akrual yang diadopsi dari studi PwC (2014). Sedangkan kuesioner untuk mengukur kualitas transparansi fiskal dikembangkan dari studi (IMF, 2014; Mueller dkk, 2015; Ionescu \& Buhur, 2016). Dalam kuesioner ini, responden diminta untuk menilai 24 indikator terkait efektivitas penerapan akrual. Kusioner menggunakan pendekatan lima skala Likert (Sugiyono, 2011). Pengujian validitas dan reliabilitas instrumen penelitian ini menggunakan pendekatan SEM. Menurut Hair dkk, (2014) nilai muatan faktor standar (SFL) $\geq 0,50$ sudah dapat dinyatakan signifikan dan valid mengukur indikator penelitian. Sedangkan pengujian reliabilitas menggunakan pendekatan ukuran Construct Relibility (CR) dan Variance Extracted (VE). Variabel atau konstruk dinyatakan mempunyai reliabilitas yang baik, jika nilai CR $\geq$ 
0,70, dan nilai $V E \geq 0,50$ (Ghozali, 2014). Hasil pengukuran secara statistik disajikan pada Tabel 1.

\section{HASIL PENGUKURAN}

\subsection{Demografi Responden}

\begin{abstract}
Data Tabel 2 menunjukan informasi demografi responden penelitian. Meskipun responden pria (53.02 persen) lebih banyak dari responden wanita (46.98 persen), namun perbedaannya tidak signifikan. Dari tingkat pendidikan, mayoritas responden berpendidikan strata 1 dan 2 (89.59 persen), dengan masa kerja mayoritas lebih dari 6 tahun (63.76 persen). Berdasarkan informasi Tabel 2, menunjukan bahwa tidak ditemukan isu terkait gender, tingkat pendidikan dan pengalaman responden dalam penerapan akrual. Data menunjukan keterwakilan responden di setiap tingkatan jabatan dalam mengkonfirmasi pertanyaan tertutup dari kuesioner. Oleh karena itu, tanggapan dari responden diyakini tepat dan dapat diandalkan dalam mengambil kesimpulan penelitian.
\end{abstract}

\subsection{Uji Kecocokan Model}

Model yang dibangun dalam penelitian ini, harus diuji terlebih dahulu, apakah model tersebut dapat dinyatakan fit dengan data penelitian. Hasil pengujian kecocokan model, ditunjukan pada Tabel 3. Berdasarkan hasil pengukuran sebagaimana ditunjukan pada Tabel 3 diketahui nilai NFI, NNFI, CFI, IFI, RFI, GFI, AGFI lebih besar sama dengan 0,90 dan nilai Chi-square 0,0683 besar sama dengan 0.05, dan nilai RMSEA $=0,0000$ kecil dari 0.08 artinya kecocokan model ini sangat baik (good fit). Sedangkan nilai SRMR $=0,088 \geq 0,05$ menunjukkan kecocokan model tidak baik (not fit). 9 dari 10 indikator kecocokan menunjukan hasil yang baik, sehingga dapat disimpulkan model penelitian ini memiliki tingkat kecocokan yang sangat baik. Setelah model dinyatakan fit, selanjutnya dilakukan pengujian hipotesis, hasilnya ditunjukan pada Tabel 4.

\subsection{Pengujian Hipotesis Penelitian.}

Data Tabel 4, menunjukan hipotesis $\mathrm{H}_{0}$ ditolak dan $\mathrm{H}_{1}$ diterima, karena nilai dari t-hitung sebesar 7,24 pada tingkat keyakinan 95 persen dan tingkat risiko kesalahan 5 persen, ternyata lebih besar dari nilai minimal t-tabel sebesar 1,96 . Artinya terdapat hubungan positif antara efektivitas penerapan akuntansi akrual dan kualitas transparansi fiskal. Sedangkan nilai loading factors sebesar 0,54 menunjukan bahwa efektivitas penerapan akuntansi akrual berpengaruh positif sebesar 54 persen terhadap kualitas transparansi fiskal.

\section{PEMBAHASAN DAN IMPLIKASI PENELITIAN}

\subsection{Efektivitas Penerapan Basis Akrual.}

Hasil penelitian sebagaimana ditunjukan Tabel 5, dapat disimpulkan bahwa efektivitas penerapan basis akrual pada sistem akuntansi pemerintah Indonesia masih berada pada level cukup dengan skor rata-rata 3,41 dari skala 5 . Kondisi ini dapat dijelaskan, Pertama, dimensi Policies dengan skor 3,41 menunjukan kebijakan atau pedoman akuntansi yang dimiliki K/L masih dalam kategori cukup. 31,76 persen $\mathrm{K} / \mathrm{L}$ belum memiliki kebijakan atau pedoman akuntansi yang memadai. Indikator adapting existing financial rules and regulations di 27,06 persen K/L belum secara maksimal mengadaptasi peraturan pemerintah yang ada. Begitu pula dengan indikator developing comprehensive guidance and manuals belum optimal di 47,06 persen K/L.

Kedua, dimensi Processes dengan skor 3,60 menunjukan proses transisi dari basis kas ke basis akrual sudah baik, namun di 27,95 persen K/L prosesnya belum optimal. Hal ini ditunjukan dari indikator setting up data collection procedures masih dikategorikan cukup, terdapat 40,89 persen $\mathrm{K} / \mathrm{L}$ belum menyiapkan daftar identifikasi transaksi penyesuaian untuk pos-pos akrual secara baik. Sementara itu, indikator ensuring compliance with existing regulatory framework masih dikategorikan cukup, 69,41 persen K/L menyatakan bahwa auditor internal belum maksimal melakukan reviu laporan keuangan secara paralel dengan proses penyusunan laporan keuangan.

Ketiga, dimensi People dengan skor rata-rata 3,26 masih berada di level cukup. Hal ini menunjukan bahwa pelaksanaan pelatihan akuntansi akrual bagi pegawai pengelola keuangan belum terencana dengan baik. Terlihat dari indikator ensuring political commitment, increasing staff and public awareness masih dikategorikan cukup, dimana 58,82 persen $\mathrm{K} / \mathrm{L}$ menyatakan bahwa kebijakan dan dukungan anggaran belum maksimal. Indikator building up public sector accountants expertise juga masih dalam kategori cukup, 37,65 persen $\mathrm{K} / \mathrm{L}$ menyatakan belum optimal dalam mengirimkan pegawainya pada berbagai program pelatihan yang diselenggarakan pemerintah pusat. Untuk indikator developing training programes and allowing knowledge transfer 
juga masih dikategorikan cukup, dimana pelatihan akrual belum dilaksanakan secara terprogram dan terencana.

Keempat, dimensi Systems dengan skor ratarata 3,38 menunjukan dukungan pemerintah dalam mengembangkan teknologi informasi masih dikategorikan cukup, dimana 32,35 persen $\mathrm{K} / \mathrm{L}$ belum optimal memanfaatkan teknologi informasi dalam proses implementasi. Hal ini ditunjukan dari indikator translating organizational processes into the IT environment masih dikategorikan cukup, artinya di 27,06 persen $\mathrm{K} / \mathrm{L}$, sistem aplikasi yang digunakan belum diintegrasikan secara penuh dan terotomatisasi dengan sistem aplikasi yang disediakan oleh Kementerian Keuangan.

\subsection{Kualitas Transparansi Fiskal Pemerintah}

Menariknya, temuan penelitian yang ditunjukan Tabel 6 mengungkapkan, meskipun efektivitas penerapan basis akrual berada di level cukup, namun kualitas transparansi fiskal pemerintah sudah berada di level baik. Hasil analisis dari skor tanggapan responden dapat dijelaskan sebagai berikut. Pertama, dimensi Fiscal Reporting dengan skor rata-rata 3,94, menunjukan bahwa Laporan Keuangan dan Laporan Kinerja Pemerintah sudah disajikan dengan komprehensif, relevan, tepat waktu, dan dapat diandalkan, meskipun di 21,24 persen K/L masih belum optimal. Isunya adalah, di 48,24 persen $\mathrm{K} / \mathrm{L}$ laporan keuangan belum optimal digunakan untuk pengambilan keputusan strategis organisasi. Kedua, dimensi Fiscal Forecasting and Budgeting dengan skor rata-rata 3,64 menunjukan kemampuan perkiraan fiskal dan anggaran pemerintah dalam laporan keuangan telah sesuai dengan tujuan dan maksud kebijakan pemerintah yang disajikan secara komprehensif, tepat waktu, dan dapat dipercaya. Ketiga, dimensi Fiscal Risk Analysis and Management dengan skor rata-rata 3,27 masih berada di level cukup. Artinya pemerintah belum optimal mengungkapkan, menganalisa, dan mengelola risiko terhadap anggaran yang dikelolanya. Hal ini ditunjukan dari indikator risk disclosure and analysis masih dikategorikan cukup, terdapat 64,70 persen $\mathrm{K} / \mathrm{L}$ belum optimal dalam penyajian informasi resiko terhadap kegagalan penyerapan anggaran dan target penerimaan. Untuk indikator risk management juga masih dikategorikan cukup, terdapat 54,12 persen $\mathrm{K} / \mathrm{L}$ belum optimal dalam memitigasi resiko kegagalan penyerapan anggaran dan capaian target penerimaan. Hal yang sama juga ditunjukan oleh indikator fiscal coordination dengan kategori cukup, terdapat 35,29 persen K/L belum optimal dalam mengkoordinasikan tidak tercapainya target penyerapan anggaran dan target penerimaan dengan pihak-pihak terkait.

\section{KESIMPULAN DAN SARAN}

Secara umum efektivitas penerapan basis akrual pada entitas akuntansi di pemerintah pusat (K/L) di Indonesia belum optimal. Meskipun dalam konteks Policies, People, dan Systems masih berada di level cukup, namun transparansi fiskal pemerintah sudah berada di level yang baik. Temuan penelitian ini, mendukung pendapat (Lye dkk, 2005; Harun \& Robinson, 2010; Adhikari \& Mellemvik, 2011; Harun dkk, 2012; Upping \& Oliver, 2012; Azmi \& Mohamed, 2014), bahwa implementasi akrual pada sektor publik khususnya di sektor pemerintahan bukanlah pekerjaan yang mudah.

Temuan ini sebagai bukti empiris bahwa implementasi basis akrual pada sistem akuntansi pemerintah memberikan dampak yang positif terhadap peningkatan kualitas transparansi fiskal pemerintah. Dalam penelitian ini, pengaruh tersebut sangat siginifikan yakni sebesar 54 persen. Hasil penelitian ini mendukung kesimpulan studi Lampe dkk, (2015) dan Ahmad dkk, (2015) bahwa penerapan akuntansi akrual pada sektor publik dapat memberikan manfaat positif terhadap transparansi fiskal berupa kemudahan mendapatkan akses informasi yang akurat untuk tujuan pertanggungjawaban pemerintah.

Temuan penelitian ini dapat menjadi masukan bagi pemerintah Indonesia dan memberikan bermanfaat sebagai referensi bagi pemerintah negara lain yang telah menerapkan atau sedang melakukan transisi dari basis kas ke basis akrual, diantaranya: (1) Pemerintah harus membuat kebijakan akuntansi dalam bentuk panduan teknis untuk masing-masing K/L sebagai pedoman bagi seluruh entitas akuntansi. (2) Untuk mengawal proses implementasi basis akrual, maka pemerintah harus mengoptimalkan fungsi internal auditor dalam mereviu dan menelaah laporan keuangan agar laporan keuangan sesuai dengan framework peraturan yang ada. (3) Untuk meningkatkan kompetensi pegawai atau akuntan pemerintah agar menyediakan anggaran untuk program pelatihan yang memadai. (4) Pemerintah harus membuat kebijakan terkait optimalisasi penggunaan sistem informasi melalui penyediaan sarana dan prasarana teknologi informasi. (5) Pemerintah harus menerapkan manajemen risiko pengelolaan anggaran dalam rangka meningkatkan kualitas transparansi fiskal. 


\section{IMPLIKASI DAN KETERBATASAN}

Implikasi teoritikal dari studi ini adalah sebagai konfirmasi terhadap studi Harun dkk, (2012), dugaan bahwa praktik akrual, lebih dominan karena faktor regulasi, dimana siap ataupun tidak siap seluruh entititas wajib melaksanakan praktik tersebut sebagai regulasi dari amanah undang-undang yang telah ditetapkan pemerintah. Artinya tekanan kelembagaan (isomorphis kohersif) (DiMaggio \& Powell, 1983; Dedoulis, 2016) masih relevan dan terbukti oleh penelitian ini.

Penelitian ini tentu memiliki keterbatasan. Pertama, meskipun survei dalam penelitian ini sudah di lengkapi dengan wawancara, namun tidak dapat dipastikan responden memberikan jawaban sesuai dengan kondisi yang sesungguhnya. Sehingga penelitian berikutnya disarankan untuk menambahkan proses observasi langsung pada unit analisis. Kedua, hasil penelitian ini tidak dapat digenereralisasikan pada pemerintah di negara lain, kecuali memiliki kemiripan dalam hal budaya, politik, sosial, dan ekonomi. Sarannya, dimasa mendatang, penelitian selanjutnya mungkin dapat memperluas survei lintas negara dengan menggunakan model dan metode yang sama dengan penelitian ini.

\section{PENGHARGAAN}

Penulis ingin mengucapkan terima kasih kepada organisasi pemerintah, khususnya terhadap $85 \mathrm{~K} / \mathrm{L}$ yang bersedia memfasilitasi proses penelitian ini melalui kegiatan wawancara mendalam dengan pihak manajemen, pengisian kuesioner, dan penyediaan informasi penting lainnya untuk keperluan penelitian ini. Ucapan terima kasih khusus disampaikan kepada pimpinan dan pegawai di Direktorat Sistem Informasi Teknologi Perbendaharaan dan Direktorat Akuntansi Pelaporan Keuangan, Direktorat Jenderal Perbendaharaan, Kementerian Keuangan untuk dukungannya menyediakan data-data lainnya yang dibutuhkan dan proses sharing knowledge sehingga mendukung kelancaran proses penelitian ini.

\section{DAFTAR PUSTAKA}

Adam, A. (2015). Fiscal transparency in the European Union. Theoretical and Applied Economics, XXII (2015), 1(602), 227-232.

Adhikari, P. \& Mellemvik, F. (2011). The rise and fall of accruals: a case of Nepalese Central. Journal of Accounting in Emerging Economies, 1(2), 123-143, DOI:10.1108/ 20421161111138495.

Ahmad, N. N., Mazlan, S. N., Ahmad, S. D. \& Pangat, M. H. (2015). Challenges of accrual accounting implementation in Malaysian Accountant General's Department. International Journal of Business, Economics and Law, 8(1), 113-117.

Aidoo-Buameh, J. (2014). Political willingness to implement public sector financial management reforms in Ghana - Accrual Basis of Accounting. Accounting and Finance Research, 3(1), 96-105, DOI:10.5430/afr.v3n1p96.

Albu, C. N., Albu, N., \& Alexander, D. (2014). When global accounting standards meet the local contex Insights from an emerging economy. Critical Perspectives on Accounting, 25(6), 489510, DOI:10.1016/j.cpa.2013.03.005.

Alt, J. E. and Lassen, D. D. (2003). Fiscal transparency and fiscal policy outcomes in OECD countries. Copenhagen: Economic Policy Research Unit.

Amriani, T. N. (2014). Menyongsong penerapan akuntansi pemerintahan berbasis akrual. Jakarta: Badan Pendidikan dan Pelatihan Keuangan, Kementerian Keuangan.

Azmi, A. H. \& Mohamed, N. (2014). Readiness of Malaysian public sector employees in moving towards accrual accounting for improve accountability: The case of Ministry of Education (MOE). Procedia-Social and Behavioral Sciences, 164, 106-111, DOI:10.1016/j.sbspro.2014.11.057.

Baker, R.O.N. \& Rennie, M.D. (2006). Forces leading to the adoption of accrual accounting by the Canadian federal government: an institutional perspective*/Les forces Ayant Mené L'administration Fédérale Canadienne À adopter La comptabilité D'exercice: une perspective institutionnelle. Canadian Accounting Perspectives, 5(1), 83-112, DOI: 10.1506/206K-RV7L-2JMN-W3D3

Ball, A. \& Craig, R. (2010). Using neoinstitutionalism to advance social and environmental accounting. Critical Perspectives on Accounting, 283-293, DOI:10.1016/j.cpa.2009.11.006.

Barton, A. (2007). Accrual accounting and budgeting systems issues in Australian governments. Australian Accounting Review, 17(41), 38-50, DOI:10.1111/ j.1835-2561.2007.tb00452.x. 
Bastani, P., Abolhalaj, M., jelodar, H. M. \& Ramezanian, M. (2012). Role of accrual accounting in report transparency and accountability promotion in Iranian public health sector. Middle-East Journal of Scientific Research, 12(8), 1097-1101, DOI: 10.5829/idosi.mejsr.2012.12.8.7129.

Beechy, T. H. (2007). Does Full Accrual Accounting Enhance Accountability? The Innovation Journal: The Public Sector Innovation Journal, 12(3), 1-18.

Bernothn, K. \& Wolff, G. B. (2008). Fool the markets? creative accounting, fiscal transparency and sovereign risk premia. Scottish Journal of Political Economy, 55, 465-487, DOI:10.1111/j.1467-9485.2008. 00462.x.

Badan Pemeriksa Keuangan. (2016). Laporan hasil review atas pelaksanaan transparansi fiskal tahun 2015. Jakarta: Badan Pemeriksa Keuangan RI.

Badan Pemeriksa Keuangan. (2017). Ikhtisar hasil pemeriksaan semester I tahun 2016. Jakarta: Badan Pemeriksa Keuangan RI.

Carpenter, V. L. \& Feroz, E. H. (2001). Institutional theory and accounting rule choice: An analysis of four US state governments' decisions to adopt generally accepted accounting principles. Accounting Organizations and Society, 26(7-8), 565-596, DOI:10.1016/S0361-3682(00)00038-6.

Cavanagh, J., Flynn, S. \& Moretti, D. (2016). Implementing accrual accounting in the public sector. International Monetary Fund, Fiscal Affairs Department.

Chan, J. L. (2003). Government accounting with Chinese characteristics and challenges. Public Money \& Management, 36(3), pp.201-208, DOI:10.1080/09540962. 2016.1133975.

Cottarelli, C. (2012). Fiscal transparency, accountability, and risk. Fiscal Affairs Department.

Deaconu, A., Nistor, C. S. \& Filip, C. I. (2009). The effect of transiting from cash accounting to accrual accounting on performance in the public sector. Studia Universitatis Babes_Bolyai Oeconomica, Volume. 54, pp. 115-129.

Dechow, P. M. \& Skinner, D. J. (2000). Earnings management: Reconciling the views of accounting academics, practitioners, and regulators. American Accounting Association, 14(2), 235-250, DOI:10.2139/ssrn.218959.
Dedoulis, E. (2016). Institutional formations and the Anglo-Americanization of local auditing practices the case of Greece. Accounting Forum, 40(1),

29-44, DOI:10.1016/j.accfor.2015.11.003.

Dillard, J. F., Rigsby, J. T. \& Goodman, C. (2004). The making and remaking of organization context: Duality and the institutionalization process. Accounting Auditing \& Accountability Journal, 506-542, DOI:10.1108/09513570410554542.

DiMaggio, P. J. \& Powell, W. W. (1983). The iron cage revisited: institutional isomorphism and collective rationality in organizational fields. American Sociological Review, 48(2), 147-160.

Ernst \& Young. (2012). Overview and comparison of public accounting and auditing practices in the $27 \mathrm{eu}$. Brussels: Ernst \& Young.

Firmansyah. (2016). Penerapan akuntansi pemerintah berbasis akrual, tonggak sejarah penciptaan pengelolaan keuangan yang kredibel, transparan dan akuntabel. Treasury Indonesia, 24-26.

Ghozali, I. (2014), "Structural equation modeling: teori, konsep dan aplikasi dengan program LISREL 9.10. Semarang: Badan Penerbit UNDIP.

Giovanelli, L., Rotondo, F. \& Caffù, S. (2016). Implementing accrual accounting in Italian universities: critical aspects of an information system. In D. Mancini, R. P. Dameri, \& E. Bonollo, Strengthening Information and Control Systems: The Synergy Between Information Technology and Accounting Models (p.190). Springer International Publishing.

Gnanarajah, R. (2014). Cash versus accrual basis of accounting: an introduction", congressional research service.

Granickas, K. (2013). Fiscal transparency and open government data. ePSIplatform.

Hair, J. F., Hufit, G. M., Ringle, C. M. \& Sarstedt, M. (2014). A primer on partial least squares structural equation modeling (PLS-SEM). Los Angeles: SAGE Publications, Inc.

Halim, A. \& Kusufi, S. (2012). Teori, konsep, dan aplikasi akuntansi sektor publik, dari anggaran hingga laporan keuangan dari pemerintah hingga tempat ibadah. Jakarta: Salemba Empat.

Harun, H., Van Peursem, K. \& Eggleton. (2012). Institutionalization of accrual accounting in the Indonesian public sector. Journal of 
Accounting \& Organizational Change, 8 (3), 257-285, DOI:10.1108/ 18325911211258308.

Harun, H. \& Robinson, P. (2010). The adoption of accrual accounting in the Indonesian public sector. Research in Accounting in Emerging Economies, Volume 10, 233 - 250, DOI:10.1108/S14793563(2010)0000010014.

Hassan, M. M. (2015). Transformation to moreaccrual-based accounting practices in Indonesian government. Journal of International Business Research, 14(1), 139165.

Heald, D. \& Hodges, R. (2018). Accounting for government guarantees: perspectives on fiscal transparency from four modes of accounting. Accounting and Business Research, 1-23, DOI:10.1080/ 00014788.2018.1428525.

Heshmat, A. A., Kariminiya, A., Khoshsanati, M. \& Farahani, M. A. (2015). Evaluating the accounting information quality and the usefulness of governmental financial reporting: evidence of a change from adjusted cash basis to accrual basis (Case Study: QOM Municipality). Indian Journal of Fundamental and Applied Life Sciences, 5 (S1), 4464-4471.

Hodges, R. \& Mellett, H. (2003). Reporting public sector financial results. Public Management Review, 5(1), 36-45, DOI: $10.1080 / 1461667022000028870$.

Hyndman, N. \& Connolly, C. (2011). Accruals accounting in the public sector: A road not always taken. Management Accounting Research, 22(1), 36-45, DOI:10.1016/ j.mar.2010.10.008.

IBP. (2016). International budget partnership. Diakses dari http://www.internationalbudget.org/opening -budgets/open-budget-initiative/openbudget-survey/country-info/?country=id

IMF. (2014). The fiscal transparency code. International Monetary Fund.

Ionescu, L. \& Buhur, S. (2016). The fiscal transparency In Romania and Turkey: A comparative stud., Economic Series, 45-55, DOI:10.2139/ssrn.2792578.

Irwin, T. C. (2012). Accounting devices and fiscal illusions. imf staff discussion note, SDN 12/02. Washington, DC: International Monetary Fund.
Ismail, S., Siraj, S. A. \& Baharim, S. (2018). Implementation of accrual accounting by Malaysian federal government: Are the accountants ready? Journal of Accounting \& Organizational Change, 14(2), 234-247, DOI:10.1108/JAOC-03-2017-0020.

Khan, A. \& Mayes, S. (2009). Transition to accrual accounting. International Monetary Fund Fiscal Affairs Department.

Lampe, H. W., Hilgers, D. \& Ihla, C. (2015). Does accrual accounting improve municipalities efficiency? Evidence from Germany. Applied Economics, .1-15, DOI:10.1080/00036846. 2015.1030562 .

Lounsbury, M. (2008). Institutional rationality and practice variation: New directions in the institutional analysis of practice. Accounting, Organizations and Society, 33(4-5), 349-361, DOI:10.1016/ j.aos.2007.04.001.

Lye, J., Perera, H. \& Rahman, A. (2005). The evolution of accruals-based crown (government) financial statements in New Zealand. Accounting Auditing \& Accountability Journal, 18(6), 784-815, DOI:10.1108/ 09513570510627711.

Maimunnah, M. (2016). Implementation of accrual accounting: Review of readiness and arising problem. Procedia-Social and Behavioral Sciences, 219, 480-485, DOI:10.1016/ j.sbspro.2016.05.023.

Mijatovic, B. (2015). Fiscal transparency principles and practice in Serbia. Southeast Europe Leadership for Development and Integrity.

Monteiro, B. R. \& Gomes, R. C. (2013). International experiences with accrual budgeting in the public sector. Revista Contabilidade \& Finanças, 24(62), 103-112, DOI:10.1590/ S1519-70772013000200002.

Mueller, J., Duplay, R., Eyraud, L., Harris, J., Petrie, M. \& Clerck, S. D. (2015). Philippines fiscal transparency Evaluation. Washington, D.C: International Monetery Fund (IMF).

Mulyani, S., Anugrah, F. \& Hassan, R. (2016), The critical success factors for the use of information systems and its impact on the organizational performance. International Business Management Journal, 10(4), 552-560, DOI:10.3923/ibm.2016.552.560.

Nistor, C. S. \& Deaconu, A. (2016. Public accounting history in post-communist Romania. Economic 
Research-Ekonomska Istraživanja, Volume 29(1), 623-642, DOI:10.1080/ $1331677 X .2016 .1193945$.

Pina, V., Torres, L. \& Yetano, A. (2009). Accrual accounting in EU local governments: one method, several approaches. European Accounting Review, 18, 765-807, DOI:10.1080/09638180903118694.

Poljašević, J. \& Radisavljević, D. V. (2014). Improving government Financial reporting in order to increase the transparency and efficiency of public service delivery. Journal of International Scientific Publications, Economy \& Business, 8, 611-626.

Putra, DM. (2019). Pengaruh penggunaan sistem informasi terintegrasi, peran knowledge management dan komitmen pimpinan terhadap peningkatan kualitas transparansi fiskal melalui implementasi standar akuntansi pemerintah berbasis akrual. Disertasi. Fakultas Ekonomi dan Bisnis. Universitas Padjadjaran. Bandung

PwC. (2013). Towards a new era in government accounting and reporting. PwC firms.

PwC. (2014). Collection of information related to the potential impact, including costs, of implementing accrual accounting in the public sector and technical analysis of the suitability of individual IPSAS standards. PwC firms.

Ratifah, I. \& Mulyani, S. (2015). Role of culture in the preparation stage of the implementation of accrual based accounting. International Journal of Economics, Commerce and Management, III(10), 172-180.

Rodrigues, L. L. \&Craig, R. (2007). Assessing international accounting harmonization using Hegelian dialectic, isomorphism and Foucault.
Critical Perspectives on Accounting, 18(6), 739757, DOI:10.1016/ j.cpa.2006.02.007.

Siksamat, S. and Wanitthanankun, J. (2015). Government finance statistics for fiscal transparency and sustainability: A case study of Thailand", IFC Bulletin No 39.

Sugiyono. (2011). Metode penelitian kuantitaif, kualitatif dan $R \& D$. Bandung: Alfabeta.

Sukmadilaga, C., Pratama, A. \& Mulyani, S. (2015). Good governance implementation in public sector: exploratory analysis of government financial statements disclosures across ASEAN countries. Social and Behavioral Sciences, 211, 513-518). Bali: Elsevier, DOI:10.1016/j.sbspro.2015.11.068.

Tanjeh, M. S. (2016). Factors influencing the acceptance of international public sector accounting standards in Cameroon. Accounting and Finance Research, 5 (2), 71-83, DOI:10.5430/afr.v5n2p71.

Tickell, G. (2010). Cash to accrual accounting: One nation's dilemma. International Business \& Economics Research Journal (Iber), 9 (11), 7178, DOI:10.19030/ iber.v9i11.32.

Upping, P. \& Oliver, J. (2012). Thai public universities: modernisation of accounting practices. Journal of Accounting \& Organizational Change, 8(3), 403-430, DOI:10.1108/18325911211258362.

Warren, C. S., Reeve, J. M. \& Duchac, J. E. (2014). Accounting 25e. Mason, $\mathrm{OH}$ : South-Western, Cengage Learning. 
Tabel 1. Hasil Pengujian Validitas dan Reliabilitas Instrumen Penelitian

\begin{tabular}{|c|c|c|c|c|c|}
\hline Konstruk/Dimensi/Indikator & $\begin{array}{l}\text { SFL } \\
\geq 0,5\end{array}$ & Error & $\begin{array}{c}\mathrm{CR} \geq \\
0,7\end{array}$ & $\begin{array}{c}\mathrm{VE} \geq \\
0,5\end{array}$ & Hasil \\
\hline Efektivitas Penerapan Basis Akrual & & & 0,94 & 0,80 & Reliabilitas Baik \\
\hline Policies & $\mathbf{0 , 8 0}$ & 0,36 & 0,86 & 0,68 & Reliabilitas Baik \\
\hline $\begin{array}{l}\text { 1. Adapting Existing Financial Rules and } \\
\text { Regulations }\end{array}$ & 0,99 & 0,46 & & & Validitas Baik \\
\hline 2. Documenting Accounting Policies & 0,92 & 0,12 & & & Validitas Baik \\
\hline $\begin{array}{l}\text { 3. Developing Comprehensive Guidance and } \\
\text { Manuals }\end{array}$ & 0,89 & 0,67 & & & Validitas Baik \\
\hline Processes & 1,00 & $\mathbf{0 , 0 0}$ & 0,83 & 0,57 & Reliabilitas Baik \\
\hline $\begin{array}{l}\text { 4. Managing the Transition Period and } \\
\text { Monitoring }\end{array}$ & 0,83 & 0,58 & & & Validitas Baik \\
\hline $\begin{array}{l}\text { 5. Checking Data Quality During the Reform } \\
\text { Process, Designing Quality Control } \\
\text { Procedures }\end{array}$ & 0,62 & 0,46 & & & Validitas Baik \\
\hline 6. Setting up Data Collection Procedures & 0,85 & 0,19 & & & Validitas Baik \\
\hline $\begin{array}{l}\text { 7. Ensuring Compliance with Existing } \\
\text { Regulatory Framework }\end{array}$ & 0,50 & 0,34 & & & Validitas Baik \\
\hline People & 0,91 & 0,17 & $\mathbf{0 , 8 1}$ & 0,52 & Reliabilitas Baik \\
\hline $\begin{array}{l}\text { 8. Inspiring Change of Mentalities and } \\
\text { Cultural Change }\end{array}$ & 0,71 & 0,32 & & & Validitas Baik \\
\hline $\begin{array}{l}\text { 9. Ensuring Political Commitment, Increasing } \\
\text { Staff and Public Awareness }\end{array}$ & 0,61 & 0,37 & & & Validitas Baik \\
\hline $\begin{array}{l}\text { 10. Building Up Public Sector Accountants } \\
\text { Expertise }\end{array}$ & 0,71 & 0,51 & & & Validitas Baik \\
\hline $\begin{array}{l}\text { 11. Developing Training Program and Allowing } \\
\text { Knowledge Transfer }\end{array}$ & 0,68 & 0,47 & & & Validitas Baik \\
\hline Systems & 0,86 & 0,26 & $\mathbf{0 , 8 0}$ & 0,67 & Reliabilitas Baik \\
\hline $\begin{array}{l}\text { 12. Adapting Existing IT Systems, and/or } \\
\text { Developing New IT Solutions }\end{array}$ & 0,69 & 0,05 & & & Validitas Baik \\
\hline $\begin{array}{l}\text { 13. Translating Organizational Processes Into } \\
\text { The IT Environment }\end{array}$ & 0,79 & 0,5 & & & Validitas Baik \\
\hline Kualitas Transparansi Fiskal & & & 0,93 & $\mathbf{0 , 8 1}$ & Reliabilitas Baik \\
\hline Fiscal Reporting & & & & & Reliabilitas Baik \\
\hline 1. Coverage & 0,90 & 0,23 & & & Validitas Baik \\
\hline 2. Frequency and Timeliness & 0,84 & 0,62 & & & Validitas Baik \\
\hline 3. Quality & 0,65 & 0,63 & & & Validitas Baik \\
\hline 4. Integrity & 0,87 & 0,23 & & & Validitas Baik \\
\hline Fiscal Forecasting and Budgeting & & & & & Reliabilitas Baik \\
\hline 5. Comprehensiveness & 0,70 & 0,22 & & & Validitas Baik \\
\hline 6. Orderliness & 0,86 & 0,23 & & & Validitas Baik \\
\hline 7. Policy Orientation & 0,69 & 0,35 & & & Validitas Baik \\
\hline 8. Credibility & 0,81 & 0,56 & & & Validitas Baik \\
\hline Fiscal Risk Analysis and Management & & & & & Reliabilitas Baik \\
\hline 9. Risk Disclosure and Analysis & 0,77 & 0,33 & & & Validitas Baik \\
\hline 10. Risk Management & 0,76 & 0,23 & & & Validitas Baik \\
\hline 11. Fiscal Coordination & 0,67 & 0,32 & & & Validitas Baik \\
\hline
\end{tabular}

Sumber: (Putra, 2019). 
Tabel 2. Hasil Pengujian Validitas dan Reliabilitas Instrumen Penelitian

\begin{tabular}{|c|c|c|c|c|c|c|c|}
\hline \multicolumn{2}{|c|}{ Deskripsi } & \multicolumn{2}{|l|}{ Jumlah } & \multicolumn{2}{|c|}{$\overline{\text { Deskripsi }}$} & Jumlah & $\%$ \\
\hline \multicolumn{2}{|c|}{ Kuesioner } & & & \multicolumn{4}{|c|}{ Wawancara Tatap Muka } \\
\hline \multirow[t]{3}{*}{1} & Gender & & & 4 & Level Taktikal & 3 & 3.90 \\
\hline & Laki-laki & 79 & 53.02 & 5 & Level Manajerial & 49 & 63.64 \\
\hline & Perempuan & 70 & 46.98 & 6 & Level Operasional & 25 & 32.46 \\
\hline \multirow[t]{4}{*}{2} & Tingkat Pendidikan & & & & & & \\
\hline & Diploma & 17 & 11.41 & & & & \\
\hline & Sarjana & 100 & 67.11 & & & & \\
\hline & Magister & 32 & 21.48 & & & & \\
\hline \multirow[t]{4}{*}{3} & Masa Kerja & & & & & & \\
\hline & $1-5$ tahun & 54 & 36.24 & & & & \\
\hline & $6-15$ tahun & 84 & 56.38 & & & & \\
\hline & Diatas 5 tahun & 11 & 7.38 & & & & \\
\hline
\end{tabular}

Sumber: (Putra, 2019).

Tabel 3. Hasil Pengujian Kecocokan Model Penelitian

\begin{tabular}{|c|c|c|c|c|}
\hline No & Goodness of fit index & Cut Point & Nilai & Hasil \\
\hline 1 & Chi-square & p-value $\geq 0.05$ & 0.0683 & Kecocokan baik \\
\hline 2 & RMSEA & RMSEA $\leq 0.08$ & 0.0437 & Kecocokan baik \\
\hline 3 & NFI & NFI $\geq 0.90$ & 0.93 & Kecocokan baik \\
\hline 4 & NNFI & NNFI $\geq 0.90$ & 0.99 & Kecocokan baik \\
\hline 5 & CFI & CFI $\geq 0.90$ & 0.99 & Kecocokan baik \\
\hline 6 & IFI & IFI $\geq 0.90$ & 0.99 & Kecocokan baik \\
\hline 7 & RFI & RFI $\geq 0.90$ & 0.93 & Kecocokan baik \\
\hline 8 & SRMR & SRMR $\leq 0.05$ & 0.088 & Kecocokan tidak baik \\
\hline 9 & GFI & GFI $\geq 0.90$ & 0.94 & Kecocokan baik \\
\hline 10 & AGFI & AGFI $\geq 0.90$ & 0.95 & Kecocokan baik \\
\hline
\end{tabular}

Sumber: (Putra, 2019).

Tabel 4. Hasil Pengujian Hipotesis

\begin{tabular}{|c|l|c|c|c|}
\hline Hipotesis & \multicolumn{1}{|c|}{ Path } & $\begin{array}{c}\text { T- } \\
\text { Value }\end{array}$ & Estimasi & Kesimpulan \\
\hline $\mathrm{H}_{1}$ & $\begin{array}{l}\text { Efektivitas Penerapan Basis Akrual Terhadap Kualitas } \\
\text { Transparansi Fiskal Pemerintah }\end{array}$ & 7,42 & 0.54 & $\mathrm{H}_{1}$ Diterima \\
\hline
\end{tabular}

Sumber: (Putra, 2019).

Tabel 5. Efektivitas Penerapan Basis Akuntansi Akrual

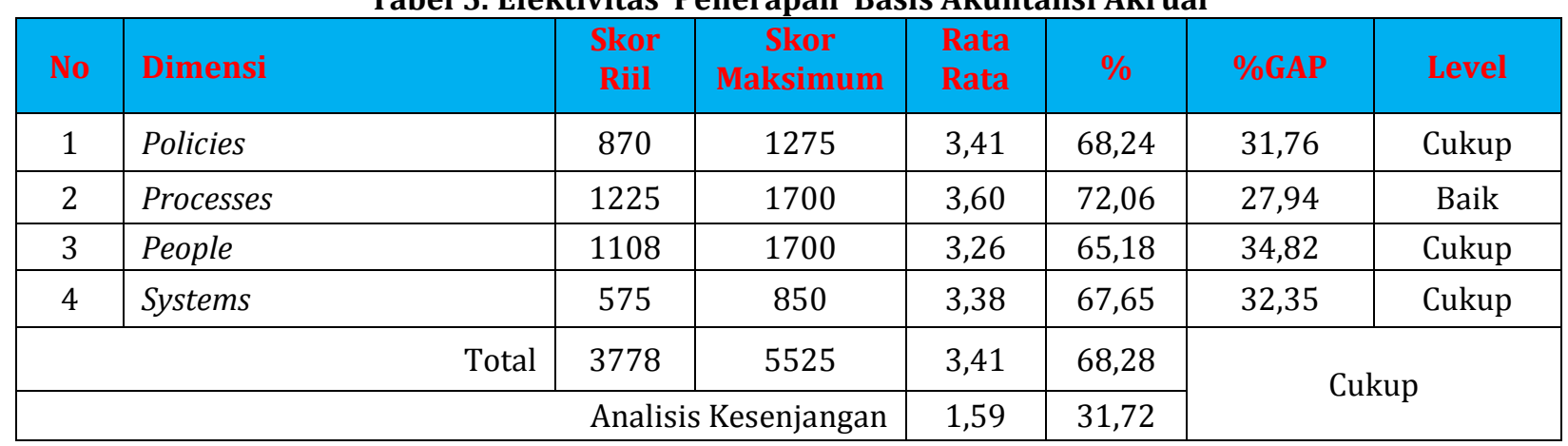

Sumber: (Putra, 2019). 
Tabel 6. Kualitas Transparansi Fiskal

\begin{tabular}{|c|c|c|c|c|c|c|c|}
\hline No & Dimensi & $\begin{array}{l}\text { Skor } \\
\text { Riil }\end{array}$ & $\begin{array}{l}\text { Skor } \\
\text { Maksimum }\end{array}$ & $\begin{array}{l}\text { Rata } \\
\text { Rata }\end{array}$ & $\%$ & $\%$ GAP & Level \\
\hline 1 & Fiscal Reporting & 1339 & 1700 & 3,94 & 78,76 & 21,24 & Baik \\
\hline 2 & Fiscal Forecasting and Budgeting & 1237 & 1700 & 3,64 & 72,76 & 27,24 & Baik \\
\hline 3 & $\begin{array}{l}\text { Fiscal Risk Analysis and } \\
\text { Management }\end{array}$ & 833 & 1275 & 3,27 & 65,33 & 34,67 & Cukup \\
\hline \multirow{2}{*}{\multicolumn{4}{|c|}{\begin{tabular}{|c|c|}
3409 & 4675 \\
Analisis Kesenjangan
\end{tabular}}} & 3,61 & 72,29 & \multirow{2}{*}{\multicolumn{2}{|c|}{ Baik }} \\
\hline & & & & 1,39 & 27,71 & & \\
\hline
\end{tabular}

Sumber: (Putra, 2019). 